\title{
Do contato aos dias atuais: sete décadas de notícias sobre os Xetá da Serra dos Dourados
}

Gian Carlo Teixeira Leite

\section{RESUMO}

Neste trabalho pretendo apresentar um estudo sobre as representações que se construíram sobre os índios Xetá, povo tupi do noroeste do Paraná, na imprensa escrita. Com o recorte temporal compreendido desde a efetivação do contato do Estado com os Xetá (em meados da década de 1940) até os dias atuais, a pesquisa teve por objetivo identificar e analisar as imagens produzidas sobre o grupo em jornais e revistas, e mais recentemente, na internet, que ao todo, somam 65 publicações. A partir da articulação feita entre a leitura deste material e os dados obtidos sobre o grupo através de fontes etnográficas e históricas, foi possível analisar as transformações pelas quais tais imagens passaram ao longo de sete décadas. $\mathrm{O}$ resultado obtido apresentase subdivido em três partes que correspondem a momentos distintos em que os Xetá foram representados como "índios selvagens sobreviventes da idade-da-pedra”, "índios aculturados sobreviventes do extermínio" e, mais recentemente, como "índios ressurgidos".

Palavras-chave: Xetá; Representação; Jornalismo.

\section{ABSTRACT}

The present work intends to present a study on the representations that were produced on the Xetá Indians, tupi people of the northwest of Paraná, in the written press. With the

\footnotetext{
Mestrando do PPGA/UFPR. E-mail para contato: giancarlotl1989@gmail.com
} 
temporal cut between the effective contact of the State with the Xetá (in the mid-1940s) to the present day, this monograph aimed at identifying and analyzing the images produced on the group in newspapers and magazines, and more recently, on the internet, which in total, they are 65 publications. From the articulation made between the reading of this material and the data obtained in the group through ethnographic and historical sources, it was possible to analyze the transformations through which these images passed for seven decades. The result obtained is subdivided into three parts corresponding to distinct moments in which the Xetá were represented as "living stone age savages", "acculturated indians surviving the extermination", and more recently as "resurgent indians".

Key-words: Xetá; Representation; Journalism.

Os Xetá são um grupo indígena de língua tupi-guarani que habitava a região da Serra dos Dourados, no noroeste do Paraná, quando em meados da década de 1940, agentes estatais e empresas privadas engendraram a conquista de seu território. Trata-se de um processo de colonização que ao expandir plantações de café à região, acaba invadindo e usurpando a extensão territorial tradicionalmente habitada pelo grupo. A violência com que se deu tal processo submeteu os Xetá a uma "tecnologia do contato e das remoções" que resultou em ações específicas de extermínio, redução populacional, envenenamentos e deslocamento compulsório de seu território (LIMA, 2016, p. 29). Estimados em cerca de 250 pessoas (cf. FERNANDES, 1959, p. 31), no curto espaço de uma década, 1950-1960, os Xetá foram reduzidos a poucos sobreviventes, desterrados, e "jogados ao esquecimento" a partir da Ditadura Militar (CNV, 2014, vol. 2, p. 220). Amparado na Lei no 2.889/1956, tal processo foi qualificado como genocídio pelo Ministério Público do Paraná no âmbito da Comissão Estadual da 
Verdade (CEV-PR, 2017, p. 143).

A partir da década de 1990, os Xetá passam a subverter a imagem de povo extinto que vinha se consolidando desde a sua retirada da Serra dos Dourados. Por meio da realização de encontros entre os sobreviventes e seus descendentes, os Xetá passam a se articular politicamente delineando um novo cenário onde reivindicam publicamente ao Estado, como medidas de reparação aos danos causados, o reconhecimento étnico, a valorização da memória e a demarcação territorial. Este período marca o início de um notável processo de recuperação demográfica, dado que de 1997 a 2004, a população do grupo praticamente dobrou (FUNAI, 2014, p. 70-71).

Atualmente, segundo Pacheco (2018), a partir do último levantamento feito pelo cacique do grupo, Dival da Silva, em 2016, os Xetá totalizam cerca de 200 pessoas. Ainda segundo o autor, a documentação e literatura conjugadas com indicações obtidas entre lideranças do grupo informa que os Xetá, ainda sem um território próprio, vivem dispersos em

\footnotetext{
áreas indígenas e cidades do Paraná - TI São Jerônimo (São Jerônimo da Serra), TI Yvyporã/Laranjinha (Santa Amélia), TI Marrecas dos Índios (Guarapuava), TI Mangueirinha (Mangueirinha), TI Rio das Cobras (Nova Laranjeiras), Aldeia Urbana Kakané Porã (Curitiba), municípios de Curitiba (bairro Pilarzinho), Almirante Tamandaré (região metropolitana de Curitiba), Douradina e Umuarama (noroeste paranaense/Serra dos Dourados) e Guaratuba (litoral) - e em Santa Catarina - TI Chapecó (Ipuaçu, oeste).
}

A partir deste panorama sumariamente apresentado acerca do grupo, este artigo busca sintetizar os resultados obtidos na pesquisa desenvolvida como monografia de conclusão do curso de 
graduação em ciências sociais pela UFPR em 2017 (cf. LEITE, 2017). ${ }^{2}$

\section{O percurso da pesquisa}

Esta pesquisa objetivou mapear e analisar as notícias e reportagens que foram publicadas sobre o Xetá, em jornais, revistas, e mais recentemente na internet. $\mathrm{O}$ recorte temporal compreende a efetivação do contato do Estado com o grupo, em meados da década de 1940, e alcança os dias atuais. Assim sendo, a localização dessas publicações se colocou como fase inicial e necessária para a etapa seguinte, que era a de análise e escrita.

Em um primeiro momento, então, fez-se necessária a busca por documentação jornalística em instituições tais como Biblioteca Pública do Paraná, Museu Paranaense, Museu de Arqueologia e Etnologia da Universidade Federal do Paraná (MAE-UFPR) e Círculo de Estudos Bandeirantes, todos sediados em Curitiba. Além de localizar tais materiais nessas instituições, foi necessário o processo de digitalização. Contudo foi na internet que a maioria das notícias que servem como fontes para esta pesquisa foi encontrada. No que se refere à pesquisa online, ela se deu de duas formas. Em alguns casos, aproveitando o serviço de busca oferecido pela Google, por meio de palavras-chave, foi possível o redirecionamento a sites que produziram algum tipo de conteúdo jornalístico sobre o grupo. A maioria, no entanto, foi obtida através do acervo digital mantido e disponibilizado pelo Instituto Socioambiental - ISA e pelo Armazém Memória em suas

${ }^{2}$ Intitulado "Do contato aos dias atuais: sete décadas de notícias sobre os Xetá da Serra dos Dourados”, a monografia foi realizada sob orientação da Prof. Drª. Edilene Coffaci de Lima, a quem sou muito grato. 
respectivas páginas na internet. ${ }^{3}$

Uma vez obtidas as reportagens, que no total somam 65, elas foram organizadas cronologicamente, e lidas de modo a identificar que representações foram construídas sobre os Xetá. A partir da articulação feita entre a leitura dos jornais e os dados obtidos sobre o grupo através de fontes etnográficas e históricas, foi possível analisar as transformações pelas quais tais imagens passaram ao longo de sete décadas.

De caráter estritamente documental, esta investigação caracteriza-se por se desenvolver numa condição em que o arquivo é tomado como campo, constituindo-se como um cenário onde podem ser buscados objetos relevantes para a reflexão antropológica (FREHSE, 2005, p. 132). Comparada à noção de campo predominante na tradição antropológica que encontra no método malinowskiano a referência canônica para a produção de dados, o arquivo enquanto campo se apresenta peculiarmente. Enquanto a partir de Malinowski encontra-se a "observação participante", no arquivo,

embora sem poder participar fisicamente, o pesquisador observa, lança mão da visão, e por meio dela, lê textos, contempla imagens, inquire a materialidade da documentação e o seu conteúdo (p. 136).

${ }^{3}$ O ISA é uma instituição não governamental que desde 1994 atua em defesa de questões sociais relativas ao meio ambiente, ao patrimônio cultural e aos direitos dos povos. Em sua página “Povos Indígenas do Brasil”, onde reúne informações sobre diversos povos indígenas do país, encontra-se uma sessão em que estão disponíveis notícias jornalísticas sobre estes povos. Já o Armazém Memória é um acervo digital, construído coletivamente para manutenção de bibliotecas públicas virtuais interligadas em um sistema de busca direto de conteúdos. Em sua página de internet encontram-se reunidos coleções de periódicos, depoimentos, livros, vídeos, áudios, artigos, documentos e imagens, bem como obras de natureza histórica, jurídica e educativa, com foco nos direitos humanos. $\mathrm{O}$ acesso à sua hemeroteca de temática indígena permitiu encontrar diversos registros jornalísticos sobre os Xetá, em que se destaca, o acervo completo do Jornal Porantim publicado pelo CIMI - Conselho Indigenista Missionário. 
Dessa forma, nesta modalidade de pesquisa, embora não se tenha uma situação de contato íntimo com os pesquisados, se estabelece um "corpo a corpo com o arquivo" em que é possível explorar um espaço de interlocução com os discursos que integram a documentação. Dessa forma, foi com a atenção voltada à observação e à leitura das reportagens nos arquivos, que pude analisar em meio aos discursos enunciados nos jornais, que representações foram forjadas sobre os Xetá, cujo resultado apresento dividido em três partes: "Os Sobreviventes da Idade da Pedra”, “Os Sobreviventes do Extermínio” e “Índios Ressurgidos”.

\section{“Os Sobreviventes da Idade da Pedra”}

Nesta parte analiso as primeiras publicações, compreendidas dentro do recorte temporal que se inicia na década de 1950 e alcança o final da década $1960,{ }^{4}$ sendo este um período em que as companhias de colonização já estavam invadindo a Serra dos Dourados. Tendo como plano de fundo histórico o tema do contato, a espoliação das terras e a denúncia de um extermínio em curso, as notícias e reportagens começam a produzir narrativas em que se sobressai a imagem de que os Xetá seriam “selvagens”, “primitivos” e "sobreviventes da Idade da Pedra”.

Assim, os repórteres da Revista da Guaíra que

${ }^{4}$ É necessário pontuar, que embora a divisão do artigo siga uma ordem cronológica delimitada por décadas específicas, esta não deve ser vista como uma segmentação rígida e fechada em si mesma. Assim, algumas representações que estão circunscritas dentro de um capítulo específico podem aparecer, ao menos incidentalmente, em fontes analisadas de outro capítulo. No entanto, é ao observar o panorama das representações identificadas na documentação jornalística que se percebe que algumas imagens preponderam e aparecem com mais ênfase dentro de um contexto específico. Assim sendo, a estruturação deste trabalho está feita de acordo com características mais salientes apresentadas pelas fontes. 
acompanharam o Serviço de Proteção aos Índios (SPI) ${ }^{5}$ em outubro de 1955, em sua "primeira expedição oficial de contato" com os Xetá na Serra dos Dourados, escreveram que após exames realizados pelo professor José Loureiro Fernandes, ${ }^{6}$ a partir do material retirado dos acampamentos Xetá encontrados na mata, era possível atestar que entre os índios em questão "sobreviviam aspectos culturais da Idade da Pedra" (NETO, 1955a). ${ }^{7}$ Uma vez que esta expedição não obteve sucesso no encontro corpo a corpo com os índios, uma segunda expedição foi organizada para o mês o seguinte, em novembro de 1955. Nesta ocasião a equipe exitou em encontrá-los, de modo que os repórteres da revista escreveram uma nova matéria, para edição da revista cuja capa trazia uma fotografia dos xetás reunidos em frente a uma de suas habitações (cf. NETO, 1955b).

Se por um lado o primitivismo é a característica produzida e enfatizada sobre os Xetá em diversos jornais e revistas da época, por outro, tem-se que tal caracterização leva em conta uma elaboração discursiva acerca da região onde o grupo vivia. Assim,

${ }^{5}$ Criado em 1910 como o órgão estatal responsável pela política indigenista brasileira, o Serviço de Proteção aos Índios (SPI) atuou no país até 1967, ano em que foi substituído pela Fundação Nacional do Índio (FUNAI).

${ }^{6}$ José Loureiro Fernandes, na época antropólogo da Universidade Federal do Paraná, foi quem propôs as primeiras características Xetá que passaram a alcançar um público mais amplo com a sua disseminação em jornais e revistas. Além disso, foi quem desde o contato mobilizou uma série de instituições em prol de medidas políticas que tivessem em conta a defesa dos índios Xetá.

${ }^{7}$ Embora conste como primeira expedição oficial de contato, de acordo com relatório produzido pelo inspetor do SPI Deocleciano de Souza Nenê, a existência dos indígenas vivendo na Serra dos Dourados já havia sido constatada pelo órgão em 1949, e reiterada em 1951, a partir de expedições realizadas por ele e pelo auxiliar Wismar da Costa Filho. Ambos solicitaram à $7^{\mathrm{a}}$ IR/SPI, medidas de proteção aos índios, que acabaram sendo negadas pelo chefe da Inspetoria, Lourival da Mota Cabral, sob alegação que já não existiam mais índios não contatados no Paraná. (CNV, 2014, vol.2, p. 224). 
na primeira reportagem da Revista da Guaíra, sobre a qual vínhamos falando, em uma das fotografias que compõe a matéria, vê-se os homens da expedição andando em fila em direção à "fabulosa floresta", e o texto da legenda informa que ali se iniciava uma “marcha para o desconhecido" (NETO, 1955a). Já a Folha de São Paulo registra: "Seu ambiente nativo era considerado dos mais primitivos" (JAGLE, 1962). Aqui, a ideia produzida implicitamente era a de que os Xetá viviam em um espaço que há milênios encontrava-se em estado prístino e intocado, pressupondo assim, a não interferência da mão ameríndia em sua composição. A perspectiva então, não sendo a de que existiria uma relação estabelecida entre o modo de vida Xetá e o seu em torno, era a de que havia uma integração simbiótica do índio a um domínio cuja agência os regia a ponto de moldar-lhes até a fisionomia. Se o “corpo embrutecido pelas selvas", como consta em uma das legendas, era o que fazia dos Xetá, “exímios arqueiros” (NETO, 1955b), é porque nestas reportagens, o primitivismo da mata é concebido de modo indissociável do primitivismo indígena.

E mais, a perspectiva naturalista que subjaz às descrições do grupo acaba por circunscrever a vida Xetá a condicionantes postos por uma ordem que os transcende, a natureza. Como par oposto à etnia qualificada como "povos naturais” (GAZETADO POVO, 1959), temos então a construção imagética do "branco" enquanto grupo de cultura civilizada, mas que na pessoa dos colonizadores gananciosos, por devastarem os feitos da natureza sem qualquer benefício próprio, corromperiam a si mesmos moralmente. "A insânia pioneira perturba a obra da natureza” destaca o jornal Gazeta do Povo (1959).

Será a partir de um viés preservacionista que as reportagens construirão o discurso de denúncia contra este 
aspecto devastador da colonização. Tal abordagem se sustenta como solução para o que aparece como sendo dois riscos iminentes colocados pelo avanço colonizador: a extinção dos índios e a desertificação do solo do noroeste paranaense. ${ }^{8}$ Assim, como via de interrupção a este projeto duplamente aniquilador da frente expansionista, algumas reportagens dedicarão parte de seus textos a chamar a atenção do Estado para que se tomem medidas administrativas urgentes. A medida sugerida, unânime nos textos, pleiteia a criação de reserva florestal onde se preservariam tanto a região quanto os índios que habitavam nela. A Folha da Manhã (1958) traz a proposta no título: “Catedrático Paranaense sugere a criação de reserva para preservação dos índios Xetá”. 9

É neste sentido que, tematizando a importância da criação do Parque Nacional de Sete Quedas, a Revista Panorama (1961) comenta que a medida possibilitaria a proteção da vida dos índios e das "matas virgens", bem como seria "um serviço que se presta à ciência, que [poderia] estudar um 'facies' vivo da pré-história brasileira". ${ }^{10}$ Formulação esta que traz à tona a reflexão de Fabian (2013, p. 52) sobre como uma abordagem evolucionista repousa em uma concepção de Tempo que não só é naturalizada, como

${ }^{8}$ É com referências diretas aos estudos de Reinhard Maack, na época geólogo e ambientalista da Universidade Federal do Paraná, que as reportagens persistirão em apontar os riscos de desertificação do solo paranaense como consequência de uma colonização predatória em uma região cuja composição da terra era imprópria para agricultura extensiva do café.

${ }^{9}$ O catedrático em questão é José Loureiro Fernandes.

${ }^{10}$ Duas tentativas de criação de uma reserva que incluísse o território tradicionalmente habitado pelos Xetá foram realizadas no período aqui analisado. A primeira foi o Parque Florestal Estadual, proposta à Assembleia Legislativa do Paraná em 1955, pelo então Deputado Estadual Antônio Lustosa de Oliveira, e vetada pelo governador Bento Munhoz da Rocha (CNV, 2014, vol. 2, p. 226). A segunda foi o Parque Nacional de Sete Quedas, criado por decreto do então presidente do país, Jânio Quadros, em maio de 1961. No entanto, não há qualquer registro que indique providências, da parte do SPI, no sentido de possibilitar o retorno daqueles quesobreviveram aolocal. (SILVA, 1998, p. 210). 
também espacializada. $O$ argumento avança no sentido de demonstrar como tal perspectiva se relaciona com a alteridade por meio de mecanismos temporais que indicam a afirmação da diferença enquanto distância. A tal produção de distanciamento, o autor denominou "negação da coetaneidade" (p. 67).

Logo, são como resquícios da perspectiva teórica evolucionista forjada no século XIX, que temos as reportagens acompanhando os estudos que delimitavam temporalmente a diferença cultural Xetá em um estágio primitivo de desenvolvimento cultural, evidenciando assim um isolamento temporal tal que os índios eram identificados como representantes vivos da pré-história brasileira. Isto exposto, não seria exagero identificar nos esforços de criação de uma reserva, junto ao desejo de se proteger os Xetá, a possibilidade de se concretizar um museu vivo, ou, um serviço em favor da manutenção das distâncias (temporal e espacial) entre "índios" e “civilizados”. Distâncias estas que funcionarão como bases subjacentes ao argumento pelo qual as reportagens, junto à denúncia, fazem apologia à criação de uma reserva por meio da qual seria possível conservar um suposto primitivismo da mata e dos Xetá - noutros termos, do "ambiente" e do "ambientado", onde "o ambientado é parte e produto do ambiente" (VIVEIROS DE CASTRO, 1999, p. 135).

Note-se ainda, que a Revista Panorama (1961) compreende a sobrevivência Xetá no território do Parque Nacional de Sete Quedas enquanto algo que estava subordinado à "resistência que [eles pudessem] oferecer a uma violenta e dissolvente mudança de 'status', ou seja seus hábitos e seus costumes". Assim, o parque foi instrumentalizado como forma de assegurar a existência de um grupo, que aos olhos da reportagem, estava inerentemente 
determinada e definida por uma suposta cultura originária. Ou seja, a um só tempo, os parques evitariam dois desertos, um enquanto impacto negativo da produção cafeeira no solo da região, o outro como processo de esvaziamento de uma cultura percebida como originalmente ameríndia.

A partir disto, trago uma avaliação contemporânea:

\begin{abstract}
Atirados de um lado para o outro pela necessidade natural e pelas necessidades do capital, os povos indígenas são vistos como registros contingentes de realidades mais eminentes. O capitalismo ou o Estado colonial disputam assim com a ordem natural o papel sobrenatural de Grande Objetivador. (VIVEIROS DE CASTRO, 1999, p. 134).
\end{abstract}

Resta que à ciência, como outro grande objetivador, ${ }^{11}$ naquele momento só lhe interessava os índios enquanto ambientados pela ordem natural, uma vez que com o capitalismo e o Estado, a situação histórica acabaria por comprometer a originalidade do seu objeto. A partir desta abordagem, a má conduta colonial do civilizado é indicada na Folha de São Paulo como aquilo que "além de prejudicar os índios, prejudica também a ciência”, o parque é concebido como "única maneira de salvá-los", o resto ficando a cargo dos "cientistas empenhados em sua preservação" (JAGLE, 1962).

A Revista Panorama fala ainda na "angústia dos cientistas para colher no menor prazo a maior soma possível de dados a respeito desses índios", e lança a pergunta: "Por quanto tempo

" “[...] nosso ideal de Ciência guia-se precisamente pelo valor da objetividade: deve-se ser capaz de especificar a parte subjetiva que entra na visão do objeto, e de não confundir isso com o objeto em si. Conhecer, para nós, é dessubjetivar tanto quanto possível. Você conhece algo bem quando é capaz de vê-lo de fora, como um objeto[...] Ou seja, para nós a boa interpretação do real é aquela em que se pode reduzir a intencionalidade do objeto a zero". (VIVEIROS DE CASTRO, 2002, p. 486-487). 
ainda sobreviverá esses índios antes de perderem inexoravelmente sua língua e sua cultura?"(COSTA, 1961). A possibilidade de existência de um parque, assim, parece funcionar como antítese e antídoto de um "pessimismo sentimental" (SAHLINS, 1997), segundo o qual a cultura Xetá seria um objeto, inescapavelmente em vias de extinção, pois estes eram tempos em que os índios não tendo passado, tampouco tinham futuro:

vaticinava-se o fim dos últimos grupos indígenas, deplorava-se sua assimilação irreversível e sua extinção tida por inelutável diante do capital que se expandia nas fronteiras do país. (CARNEIRO DA CUNHA, 2009, p. 125).

O que a historiografia sobre os Xetá conta, é que apesar das denúncias e dos apelos nacionais e internacionais para que se garantisse aos índios o território nos anos 1950, com o comando político nas mãos militares na década seguinte, a situação dos Xetá não se resolveu. Reduzidos e desterrados, a partir da Ditadura Militar os Xetá foram "jogados ao esquecimento" (CNV, 2014, vol. 2, p. 220), em suma, a situação foi tomada como um "fato consumado" (LIMA, 2016, p. 25). A consumação deste fato, a partir de então, aparecerá nas próximas publicações como transformação da imagem de primitivo: de "sobreviventes da idade da pedra", os Xetá passam à situação de últimos "sobreviventes do extermínio".

\section{“Os Sobreviventes do Extermínio"}

Nesta parte analiso as reportagens que foram publicadas desde a década de 1970 até o final da década de 1990, período este em que a extinção aparece como um fato consumado e irreversível. Em 1978, a Revista Panorama escreve uma nova matéria onde afirma terem acertado o prognóstico produzido na reportagem da década 
anterior. O texto tem início pelo seguinte parágrafo:

A descoberta dos índios Xetá, habitando a região da Serra dos Dourados, no noroeste paranaense, nos anos cinquenta do nosso século, foi um fato importantíssimo para a Ciência. Encontrar em pleno século XX uma tribo vivendo ainda na Idade da Pedra foi como se descobríssemos uma Máquina do Tempo que nos permitisse voltar à pré-história para conviver com nossos antepassados remotos. Para o bem da Ciência era necessário estudar a fundo os índios Xetá a fim de melhor entender nosso passado e nós mesmos. Como um dever a humanidade era necessário que os Xetá fossem preservados. Infelizmente nada disso aconteceu [...] (XAVIER, 1978).

O fim da reportagem anuncia o fim dos índios: “os Xetá foram destruídos para todo o sempre”.

Esta dimensão fatalista aparece como traço fundamental das representações produzidas sobre o grupo neste período, estando presente, portanto, já nos títulos das publicações: "Civilização extinguiu os Xetás” (O ESTADO DE SÃO PAULO, 1972); “O Massacre dos Xetá", da Revista Panorama (XAVIER, 1978); "Extermínio”, do Diário do Paraná (MARINS, 1981) e da Folha de Londrina (ORICOLLI, 1985); "Xetás, uma tribo em extinção" de O Estado do Paraná (TESSARI, 1985); "O Extermínio de 'todos Nós”' de O Estado do Paraná (LOPES, 1989), etc.

Esta percepção de que os Xetá seria um povo que foi massacrado no passado, e cujo futuro estaria, inexoravelmente, fadado ao fim, em boa parte dos jornais está desenvolvida nas reportagens que tematizam os poucos Xetá que não só estavam, como "restavam", vivos. Serão assim, como "restos", “remanescentes" e "últimos sobreviventes" do extermínio, que os Xetá contemporâneos às publicações serão representados, em títulos como "Últimos índios xetás visitam UFPR e se emocionam com objetos e fotos" (GAZETA DO POVO, 1994), e em diversas 
passagens: "Dos poucos Índios vivendo em estado primitivo - cerca de 200 - só restaram quatro xetás, dois dos quais não se tem notícia”, no Diário do Paraná (MARINS, 1981); "A colonização do Paraná matou barbaramente uma comunidade de índios que viviam como homens da pedra às margens do rio Ivaí. Eram os xetás. Hoje só restam oito deles", na Folha de Londrina (ATAÍDE, 1982); "De uma tribo seminômade, composta por índios caçadores e colhedores, restam somente cinco membros", no O Estado do Paraná (TESSARI, 1985).

Sobre estes poucos indivíduos que "restaram", a imagem produzida fundamenta-se numa concepção de "descaracterização cultural" e "aculturação". O caso apresentado pela Folha de Londrina (ATAIIDE, 1985) é emblemático. Em reportagem sobre o que chama de "remanescentes" Xetá, ao evocar a transformação cultural indígena que resulta do contato, define a condição Xetá como produto da aculturação. Esta mesma reportagem, cujo subtítulo, note-se, era "Mesmo juntando seus cacos os Xetá estão na UTI da história do Paraná. A colonização indiscriminada do Estado provoca o fim da raça. Irreversível", traz fotografias dos "sobreviventes", sendo que sob a imagem do indígena, Tuca, a legenda diz: "Tuka, apesar de aculturado, sente saudades da vida que levava no meio do mato." E na que retrata Ã e Kuein, assim escrevem: "Rosa $[\tilde{A}]$ e Kuen: aproximação que não deu certo - a aculturação atrapalhou a preservação da raça”. ${ }^{22}$

Esta "aproximação que não deu certo" refere-se ao episódio ocorrido na década de 1970, em que Dival de Souza, então diretor do Posto Indígena de Guarapuava, sugeriu que Ã e Kuein se

${ }^{12}$ Tuca, Kuein e Ã, estão entre os Xetá que quando crianças testemunharam e foram vítimas da violência colonizadora na Serra dos Dourados na década de 1950. Destes três, só Ã e Kuein continuam vivos. 
casassem como medida de reversão da extinção (SILVA, 1998, p. 62). Isto se explica pelo fato de que o desfecho da suposta extinção se sustenta também numa outra imagem que não se refere às mortes ocorridas no passado, mas à impossibilidade de nascimentos no futuro. O argumento, em sua maioria, está desenvolvido em parágrafos que se dedicam à descrição dos casamentos interétnicos, cujo princípio biologicista implícito orienta as noções elementares de vínculo e pertencimento étnico. O que estas imagens expõem é que se por um lado a responsabilidade pela morte dos índios ocorridas no passado é dos brancos, por outro lado, a reprodução da vida, sociedade e cultura Xetá, tornase inconcebível e impensável por causas que recaem em parte sobre o próprio grupo, apontados como aqueles que se casaram errado.

A partir daqui, vale notar que algumas reportagens parecem esboçar uma contraposição entre o destino que tiveram os objetos Xetás, e o que tiveram os próprios Xetás enquanto “objetos” de interesses científicos. Embora se diga que ambos tenham "restado", os objetos produzidos parecem ter conservado a sua importância antropológica em um nível de significância maior que aqueles que os produziram - supostamente, os vestígios da cultura materializada falariam mais da cultura do índio, que o próprio índio, o "aculturado". Não à toa, ao lado da expressão “extinção física”, O Estado do Paraná, em reportagem de Tessari (1985), faz aparecer a "extinção cultural” para caracterizar o “trágico destino" dos Xetá, onde a primeira define um processo de supressão física dos índios, e a segunda traduz-se como uma espécie de esvaziamento do conteúdo cultural ameríndio. Em suma, aos poucos que conseguiram escapar à eliminação física do corpo, a extinção era certa porque vinha num processo de violação 
que se dava na alma.

Claro está que, se nas primeiras décadas fez-se recorrente o receio de que os índios acabariam, o que fez com que se incentivasse, com teor de imediatismo, a pesquisa acadêmica sobre os Xetá, uma vez que se considera o fim físico e cultural dos índios, o que se observa nestes jornais, é que a relevância antropológica do grupo permaneceria viva tendo por referência apenas o que foram no passado, e como documento, os materiais outrora encontrados: "Da presença dos xetás, restam apenas o material coletado pela Universidade Federal”, no jornal O Estado do Paraná (TESSARI, 1985). Ataíde (1982) escreve na Folha de Londrina:

O que existe é o resultado do trabalho desenvolvido pelo professor Loureiro, que realizou um documentário único no gênero, registrando cenas da vida extremamente primitiva desse grupo indígena da era pré-cabralina.

Da perspectiva jornalística, os acontecimentos se passam como se os Xetá, enquanto figura prototípica do selvagem, tivessem valor documental deteriorado à medida que o processo de aculturação que cobre a nudez originariamente ameríndia lhes impusesse as vestes do indiferenciado caboclo brasileiro, enquanto que seus vestígios materiais guardariam intactos, porque conservados, o registro de parcial de uma cultura longínqua. Em poucas palavras, tal perspectiva poderia ser assim formulada: parte do que o Parque não pôde preservar dos Xetá como objetos, os Museus conservaram nos objetos Xetá: a sua cultura.

Na virada para o século XXI, surge uma nova imagem: o “índio ressurgido”. 


\section{“Índios Ressurgidos”}

A nova imagem de "ressurgimento" remonta ao processo iniciado em meados da década de 1990, em que oito Xetá que viveram décadas dispersos após a invasão e expropriação de suas terras e vidas, bem como seus descendentes, puderam se encontrar e se articularem politicamente em torno de reivindicações onde pautam justiça e reparação. Tal feito acontece a partir da ação conjunta entre pesquisadores da Universidade Estadual de Londrina (UEL), da Universidade Federal do Paraná (UFPR) e agentes da Fundação Nacional do Índio (FUNAI), a partir da qual foram organizados eventos que possibilitaram os primeiros (re)encontros. ${ }^{13}$ Este “retorno” dos Xetá ao cenário geopolítico paranaense encontra-se tematizado em registros jornalísticos produzidos no contexto da virada do século XX para o XXI. Sob os signos de "ressurgimento", “renascimento”, “recomeço”, “emergência étnica” e similares, constróise a nova imagem. ${ }^{14}$

Assim, O Estado de São Paulo (1999), ao falar em “reaparição” dos índios, se refere aos Xetá como um povo que emergiria da extinção a partir da pesquisa feita pela antropóloga Carmén Lúcia da Silva, da Universidade Federal do Paraná. O título vai direto ao ponto: "Oficialmente extintos, xetás reaparecem".

O jornal Porantim (SILVA, 1999) no mesmo ano traz uma

${ }^{13}$ Em julho de 1994, pesquisadores da UEL e agentes da FUNAI realizaram o "Encontro Xetá: os sobreviventes do extermínio", em São Jerônimo da Serra - PR. Já em agosto de 1997, o Instituto Socioambiental/ISA promoveu em Curitiba - PR, com apoio da Universidade Federal do Paraná, o "Encontro Xetá: Sobreviventes do Extermínio". Ainda que muitas instituições estejam implicadas no "reencontro" dos Xetá, nas reportagens é o nome da antropóloga Carmen Lúcia da Silva (UFPR) que prevalece como apoiadora e possibilitadora do "ressurgimento" Xetá.

${ }^{14}$ Segundo Arruti (2006), no mesmo período, uma alta concentração de grupos indígenas do Nordeste brasileiro passou por processos de "ressurgimento", "emergências" e similares, sendo estas designações alternativas para o que na antropologia se designa também como "etnogênese". 
matéria em que uma das partes se intitula "Uma história que recomeça”. Em 2001, o mesmo jornal lista os Xetá, ao lado de outras 29 etnias, como povos que teriam "ressurgido" nos últimos trinta anos (PORANTIM, 2001). Já em 2003, no entanto, o jornal passa a expôr uma autoimagem indígena que opta pela noção de "resistência étnica": "Nem ressurgidos nem emergentes, somos povos resistentes" (LUCHIN, 2003) é o título da reportagem cujo tema remonta a participação dos Xetá, junto a 46 outros povos indígenas, do "I Encontro Nacional de Povos em Luta Pelo Reconhecimento Étnico e Territorial”, realizado em Olinda - PE, em maio daquele ano. Uma das pautas e objetivos centrais desse encontro era fazer valer a autoidentificação étnica, e este é um princípio defendido em todas reportagens do jornal Porantim encontradas no período, de modo que, com frequência, se verifica em seus textos a presença de um elemento até então pouco tematizado: os descendentes Xetá como aqueles que estariam comprometidos com o futuro da etnia. Em duas reportagens (D. BUZATTTO; C. BUZATTO; PELIZZARI, 2007; PORANTIM, 2007) os descendentes são indicados como aqueles cujos esforços estavam orientados para dar sequência à "luta” política de lideranças recém falecidas na época.

Este tema da "resistência étnica" está diretamente associado à problemática dos conflitos territoriais. Contrariamente ao posicionamento do Jornal Porantim, cujos textos se alinham às reivindicações acionadas pela política indígena em geral, e Xetá em específico, outros veículos se colocam declaradamente contra os interesses e reivindicações territoriais Xetá. Assim, o que se tem é uma ofensiva midiática que combina argumentos produzidos contra a demarcação da terra Xetá (cf. Tribuna de Cianorte, 2009; Veja, 2013; Rocha, 2014; Canal Rural, 
2014). ${ }^{15}$ Os argumentos podem ser divididos em cinco tópicos: (1) Afirmam que os descendentes Xetá não são índios legítimos, portanto não merecedores da terra; (2) Sustentam que a demarcação da terra se configura como processo que acabaria por retirar o sustento e o trabalho e produtores locais; (3) Se valem da tese jurídica do marco temporal, segundo a qual o Estado só reconheceria como terras tradicionais aquelas que estivessem sendo ocupadas pelos índios na data da promulgação da Constituição de 1988; (4) Atacam o trabalho da Fundação Nacional do Índio - FUNAI, ao deslegitimarem os laudos de identificação da terra produzidos pelo órgão, afirmando que estes laudos carecem de rigor técnico; (5) E comentam que a terra identificada seria muita para pouco índio.

Âs vezes, em um único parágrafo é possível encontrar reunidos alguns destes tópicos:

\begin{abstract}
Desses cem autointitulados xetás, mais de 90 membros têm apenas ascendência parcial, contando também com ancestrais brancos ou de índios de outras tribos. Mas o número reduzido não havia intimidado a Funai e os apoiadores dos índios, que acharam aceitável promover no início dos anos 2000 o renascimento da etnia com uma área equivalente a do município de Niterói, no Rio de Janeiro, onde vivem quase 500.000 pessoas. Para piorar, a área reservada para os xetás é ocupada por dezenas de fazendas, a maioria de propriedade de pequenos produtores, e uma vila rural (Veja, 2013).
\end{abstract}

O agente responsável pelo "renascimento" dos Xetá, inaceitável do ponto de vista da reportagem, não seriam os próprios índios, mas a Funai. Nessa interpretação, mais uma vez, o índio como

${ }^{15}$ Em 2014, A Funai publicou estudos que reconhecem a área de ocupação tradicional dos Xetá, compreendendo parte do território em que viviam até a década de 1950 (cf. FUNAI, 2014, p. 70-71). Restam ainda, para conclusão do processo administrativo demarcatório, a expedição da Portaria Declaratória, homologação e registro da Terra Indígena. 
sujeito político some na condição de objeto da política estatal, e reaparece em cena como personagem cujo movimento seria manipulado pela Funai. Em virtude disto, resta-nos admitir com Sahlins (2004, p. 13), que de fato alguns povos, tal como os europeus, tem toda sorte ao seu lado, visto que tem o privilégio de reter o termo "Renascimento" para especificar um período da sua história no qual após reunirem-se os seus nativos, inicia-se um processo de invenção de suas tradições e de si próprios que é reconhecido como um "renascimento cultural genuíno [e] o início de um futuro progressivo.” Ao passo que quando outros grupos, tais como os Xetá, o fazem, "trata-se de um sinal de decadência cultural, uma recuperação artificial, que apenas produz o simulacro de um passado morto”. Em suma, tal como a reportagem se posiciona: um processo inaceitável.

\section{Considerações Finais}

As observações feitas ao longo desta pesquisa permitem indicar que os meios de comunicação, a imprensa escrita particularmente, ocupa um lugar fundamental para que se alcance algum conhecimento acerca das informações propagadas acerca dos Xetá.

Neste caso, tentei demonstrar que o grupo foi representado pelos jornais e revistas, nas primeiras décadas do contato, como "primitivos sobreviventes da Idade da Pedra", donde se vê, em meio aos argumentos preservacionistas, a produção de distâncias espaciais e temporais opondo "brancos” e “índios”. Já de 1970 a fins dos anos 1990, eles são tomados como poucos "índios aculturados e sobreviventes do extermínio" cuja extinção seria um fato inelutável. A partir do século XXI, no entanto, como reflexo 
da articulação política dos Xetá, os membros do grupo são identificados como aqueles que não só estariam vivos, como também em processo de "emergência étnica contra tal processo, que aparece sobre imagens de "retorno”, "recomeço”, "ressurgimento” e outros, algumas vozes se entoam nos jornais. A ofensiva, tendo por objetivo a contestação e interdição do processo de reparação territorial, cria a imagem de que os Xetá estariam almejando, e a FUNAI autorizando, a partir de laudos antropológicos duvidosos, o direito de muita terra para poucos, e ilegítimos, índios.

Nessa batalha política que se trava imageticamente. A atenção às formas com as quais os Xetás tem se apropriado de tecnologias midiáticas para a produção de uma autoimagem, pode fornecer pistas de como eles estão "indigenizando a modernidade" (SAHLINS, 1997, p. 53), de modo a afirmarem e assegurarem a própria vida. Questão relevante de ser pesquisada quando se considera a recorrência atual de relatos Xetá em que se sobressai o descontentamento no que se refere ao apagamento do grupo da história indígena sul-brasileira, bem como um notável interesse do grupo em ter a existência divulgada nos meios de comunicação.

\section{REFERÊNCIAS}

BRASIL. Comissão Nacional da Verdade. Relatório. Brasília (DF): CNV. 2014. (Relatório da Comissão Nacional da Verdade; v. 2).

CARNEIRO DA CUNHA, Manuela. Por uma história indígena e do indigenismo. In. Cultura com aspas e outros ensaios. São Paulo: Cosac Naify, 2009.

FABIAN, Johannes. O Tempo e o Outro: como a Antropologia estabelece seu objeto. Petrópolis: Editora Vozes, 2013.

FERNANDES, José L. Os índios da Serra dos Dourados (Os Xetá). 
Anais da III Reunião Brasileira de Antropologia. Recife, p. 27-46, 1959.

FREHSE, Fraya. Os informantes que jornais e fotografias revelam: para uma etnografia da civilidade nas ruas do passado. Revista Estudos Históricos, Rio de Janeiro, v. 2, n. 36, p. 131-156, jan., 2005. ISSN 2178- 494. Disponível em:

<http://bibliotecadigital.fgv.br/ojs/index.php/reh/article/view/22 47/1386>. Acesso em: o6 Fev. 2019

Fundação Nacional do Índio - FUNAI. Resumo do Relatório Circunstanciado de Identifcação e Delimitação da Terra Indígena Herarekã Xetá. Diário Oficial da União, Brasília, DF, 30 jun. 2014, Seção 1, no 122, p. 70-1.

LEITE, Gian C. T. Do contato aos dias atuais - sete décadas de notícias sobre os Xetá de Serra dos Dourados. Monografia (Graduação em Ciências Sociais)-Setor de Ciências Humanas da Universidade Federal do Paraná. Curitiba (PR). 2017.

LIMA, Edilene C. Exílios índios: sobre deslocamentos compulsórios no período militar (1964-1988). ACENO, Cuiabá (MT):PPGAS-UFMT, v.3, n. 6, p. 18-35, dez., 2016.

PACHECO, Rafael. Os Xetá e suas histórias: memória, estética, luta desde o exílio. 2018. 265 f. Dissertação (Mestrado em Antropologia) Programa de Pós-Graduação em Antropologia, Setor de Ciências Humanas, Universidade Federal do Paraná. Curitiba (PR). 2018. (Ms).

PARANÁ. Comissão Estadual da Verdade Teresa Urban. Relatório da Comissão Estadual da Verdade do Paraná. São Paulo (SP): CEV-PR; TikiBooks. 2017. (v. 1).

SAHLINS, Marshall. O pessimismo sentimental e a experiência etnográfica: porque a cultura não é um objeto em via de extinção. In: Mana - Estudos de Antropologia Social do Museu Nacional. Rio de Janeiro:UFRJ, v. 3, n. 1 e 2, 1997.

SAHLINS, Marshall. Esperando Foucault, ainda. São Paulo: Cosac Naify, 2004.

SILVA, Carmen L. Sobreviventes do Extermínio: uma etnografia das narrativas e lembranças da sociedade Xetá. Dissertação (Mestrado em Antropologia)-Centro de Filosofia e Ciências Humanas, Universidade 
Federal de Santa Catarina. Florianópolis, 1998.

VIVEIROS DE CASTRO, Eduardo. "Etnologia brasileira”. In: MICELI, Sérgio (org.). O que ler na Ciência Social brasileira (1970-1995), vol. 1: Antropologia. São Paulo: Org. Sumaré/Anpocs, p. 109-223, 1999.

VIVEIROS DE CASTRO, Eduardo. "Entrevista com Eduardo Viveiros de Castro". In. A Inconstância da Alma Selvagem. São Paulo: Cosac Naify, 2012.

\section{Documentação Jornalística}

A dúbia política indígena que pressiona o governo Dilma. Veja. o8 jun. 2013. Disponível em: http://goo.gl/428Hw6. Acesso em o6 fev. 2019.

AUDIÊNCIA discute demarcação da terra xetá. Tribuna de Cianorte. 30 out. 2009. Disponível em: http://goo.gl/ioAsCZ. Acesso em o6 fev. 2019.

ATAÍDE, Eunice. Xetá. Folha de Londrina. Londrina-PR. o8 mai., 1982.

BUZATTO, Marline D.; BUZATTO, Cleber C. \& PELIZZARI, Diego J. A saga do povo Xetá no Paraná. Porantim, n. 297, p. 14, ago., 2007 a.

CATEDRÁTICO paranaense sugere a criação de reserva para preservação dos índios Xetá. Folha da Manhã. São Paulo-SP, 19 nov., 1958.

CIVILIZAÇÃO extinguiu os Xetá. O Estado de São Paulo. São PauloSP, 27 fev., 1972.

COSTA, Samuel G. Os sobreviventes da Idade da Pedra. Revista Panorama, Curitiba - PR, ano VII, n. 11, p. 20-26, jul., 1961.

DEMARCAÇÃO de terra indígena em Ivaté (PR) pode afetar 12 mil funcionários de usina canavieira. Canal Rural o7 de jul., 2014. Disponível em: https://goo.gl/DwizoE. Acesso em o6 fev. 2019.

ENCONTRO unifica a luta e fortalece o povo Xetá. Porantim, no30o nov. 2007b, p.10. 
JAGLE, Abram. Os índios xetás estão sendo dizimados por incursões de brancos. Folha de São Paulo. São Paulo-SP, 15 nov. 1962.

LOPES, Adélia Maria. O extermínio de “Todo Nós”. O Estado do Paraná. Curitiba-PR, 26 abr. 1989.

LUCHIN, Liliane. Nem ressurgidos, nem emergentes, somos povos resistentes. Revista Porantim. n. 256, p.o8-o9, jun./jul., 2003.

MARINS, Paulo. Extermínio. Diário do Paraná. Curitiba-PR, o3 jan. 1981.

NETO, Loyola. Esta terra tem dono! : a reportagem de Guaíra participa da "Expedição da Serra dos Dourados". Revista da Guaíra, Curitiba - PR, ano VII, n.64, p. 43-48, nov. 1955 a.

NETO, Loyola. Segunda expedição a Serra dos Dourados. Revista da Guaíra. Curitiba-PR, Ano VII, n. 65, p. o8-16, dez., 1955b.

OFICIALMENTE extintos, xetás reaparecem. O Estado de São Paulo. São Paulo-SP, 15 fev. 1999.

ORICOLLI, Silvio. Os Xetá - Extermínio. Folha de Londrina. Londrina-PR, 11 nov. 1985.

ROCHA, Leonel. Funai demarca terras no Paraná e atrapalha campanha de Gleisi. Época. o6 jul. 2014. Disponível em: https://goo.gl/q6qXd2. Acesso em 30 jul. 2018.

POVOS ressurgidos: renascendo das cinzas. Porantim. n. 233, p. 19, mar., 2001.

RECUO melancólico dos Xetá na Serra dos Dourados. Gazeta do Povo. Curitiba-PR, 3 dez. 1959.

SILVA, Carmen L. Os sobreviventes do Extermínio. Jornal Porantim, no 212. Jan/Fev. 1999.

TESSARI, Francisco J. Xetás, uma tribo em extinção. O Estado do Paraná. Curitiba - PR, og jun. 1985.

ÚLTIMOS índios xetás visitam UFPR e se emocionam com objetos e fotos. Gazeta do Povo. Curitiba-PR, 10, jul 1994. 
XAVIER, Valêncio. O MASSACRE dos Xetá. Revista Panorama, Ano 28, n. 259, p. 14-17, jul., 1978. 